\title{
Phase-Separation Phenomena in Solutions of Poly(2,6- dimethyl-1,4 phenylene Oxide). II. Differential Scanning Calorimetry of Solutions in Toluene
}

\author{
D. M. KOENHEN and C. A. SMOLDERS, Twente University of \\ Technology, Enschede, The Netherlands
}

\begin{abstract}
Synopsis
The phase-separation phenomena observed in solutions of poly (2,6 dimethyl-1,4 phenylene oxide) in toluene have been investigated by differential scanning calorimetry. These measurements supplement the experimental evidence in favor of the concept that the phase transitions observed are crystallization and melting phenomena. The experiments suggest that two kinds of crystals can develop and that a seeded crystallization is possible.
\end{abstract}

\section{INTRODUCTION}

Homogeneous solutions of poly(2,6 dimethyl-1,4 phenylene oxide) (PPO*) in toluene, up to concentrations of $40 \%$ by weight, can be obtained by heating the mixture to a temperature of $110^{\circ} \mathrm{C}$. When such a solution is cooled, turbidity sets in at a temperature which depends on the cooling rate. ${ }^{1}$ When this turbid solution is again heated, it becomes clear at a temperature higher than that of incipient phase separation, but always below $110^{\circ} \mathrm{C}$. In the literature two explanations have been put forth for the phase separation phenomena observed in this system: a) liquid-liquid phase separation, after which the concentrated phase undergoes crystallization. ${ }^{1}$ b) crystallization of the polymer from the solution. ${ }^{2}$

The transitions are accompanied by a heat effect, which makes it possible to detect the transition with a differential scanning calorimeter. In this work DSC measurements are reported which supplement earlier DSC work on this system. ${ }^{3}$ The measurements were devised in such a way that the results might provide data that would help to discriminate between the two mechanisms proposed for phase separation.

\section{EXPERIMENTAL}

The apparatus used was a Perkin-Elmer DSC-1B apparatus with a liquid nitrogen subambient assembly. The solutions were made up in vacuum-sealed tubes as described earlier, ${ }^{1}$ cooled down quickly to enable the filling of the liq-

* PPO is a trademark of the General Electric Co. 


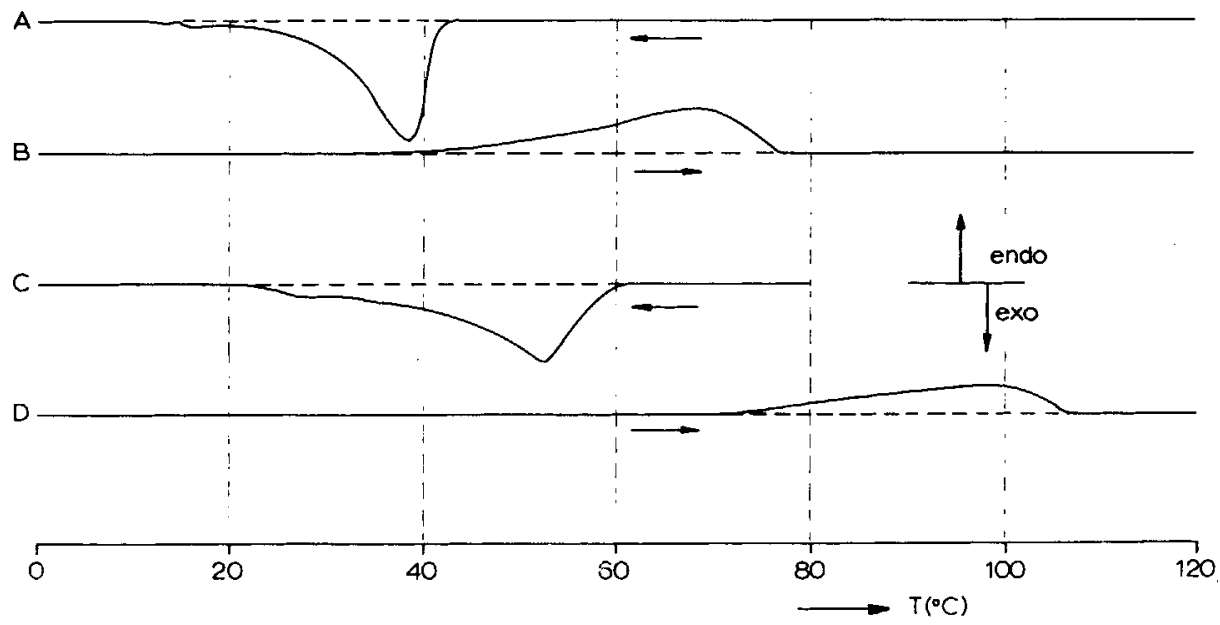

Fig. 1. DSC traces of a $40 \%$ solution of PPO in toluene.

uid-type sample pans with a semisolid polymer-solvent system. Only sample pans were used which showed no weight loss after being held at $90^{\circ} \mathrm{C}$ for 3 days. The PPO used was a narrow distribution sample characterized by $\bar{M}_{n}=35,800$, $\bar{M}_{w}=39,500$. This sample was obtained by liquid-crystal fractionation. The toluene used was Baker Analysed Reagent p.a. grade.

\section{RESULTS}

In Figure 1 some results for a 40\% w/w PPO solution are shown. Different concentrations showed parallel characteristics. The transition temperatures increase monotonically with concentration. When a solution, which has been at a temperature of $120^{\circ} \mathrm{C}$ for several hours, is cooled at a rate of $16^{\circ} \mathrm{C} / \mathrm{min}$, curve $A$ is obtained. There is an exothermic heat effect which begins at $T=42^{\circ} \mathrm{C}$. Heating this solution at a rate of $16^{\circ} \mathrm{C} / \mathrm{min}$ to $120^{\circ} \mathrm{C}$ produced curve $B$. An endotherm is shown which ends at $T=78^{\circ} \mathrm{C}$. When the solution heated up to $120^{\circ} \mathrm{C}$ is cooled again at the same rate, curve $A$ is reproduced. However, when the heating procedure of curve $B$ is stopped at $T=85^{\circ} \mathrm{C}$ (well beyond the endotherm) and the sample is cooled at a rate of $16^{\circ} \mathrm{C} / \mathrm{min}$, curve $C$ is obtained. When this solution is heated again, there is no endotherm ending at $78^{\circ} \mathrm{C}$ but one ending at $106^{\circ} \mathrm{C}$ (curve $D$ ). In this case, when heating is stopped at $85^{\circ} \mathrm{C}$ and the system is cooled, no exotherm is observed.

When the solution is cooled from $120^{\circ} \mathrm{C}$ to $0^{\circ} \mathrm{C}$ at different cooling rates and then heated at $16{ }^{\circ} \mathrm{C} / \mathrm{min}$, the curves shown in Figure 2 are obtained. With a cooling rate of $0.5^{\circ} \mathrm{C} / \mathrm{min}$ curve $E$ is obtained upon heating. This curve shows the endotherm at $106^{\circ} \mathrm{C}$. Reheating the samples directly after faster cooling $\left(1^{\circ} \mathrm{C} / \mathrm{min}\right.$ and $2{ }^{\circ} \mathrm{C} / \mathrm{min}$ ) produces a second endotherm (curves $F$ and $G$ ) at lower temperatures. After cooling at a rate of $4^{\circ} \mathrm{C} / \mathrm{min}$, reheating gives curve $H$ with a single endotherm at $78^{\circ} \mathrm{C}$. This curve is identical with that obtained after cooling at a rate of $16^{\circ} \mathrm{C} / \mathrm{min}$ (curve $B$ in Fig. 1). In curves $F$ and $G$ the lower endotherm increases in area with increasing cooling rate, whereas the other endotherm decreases. In addition the end of the lower endotherm shifts to a higher temperature. The higher endotherm ends at $106^{\circ} \mathrm{C}$ in all cases. 


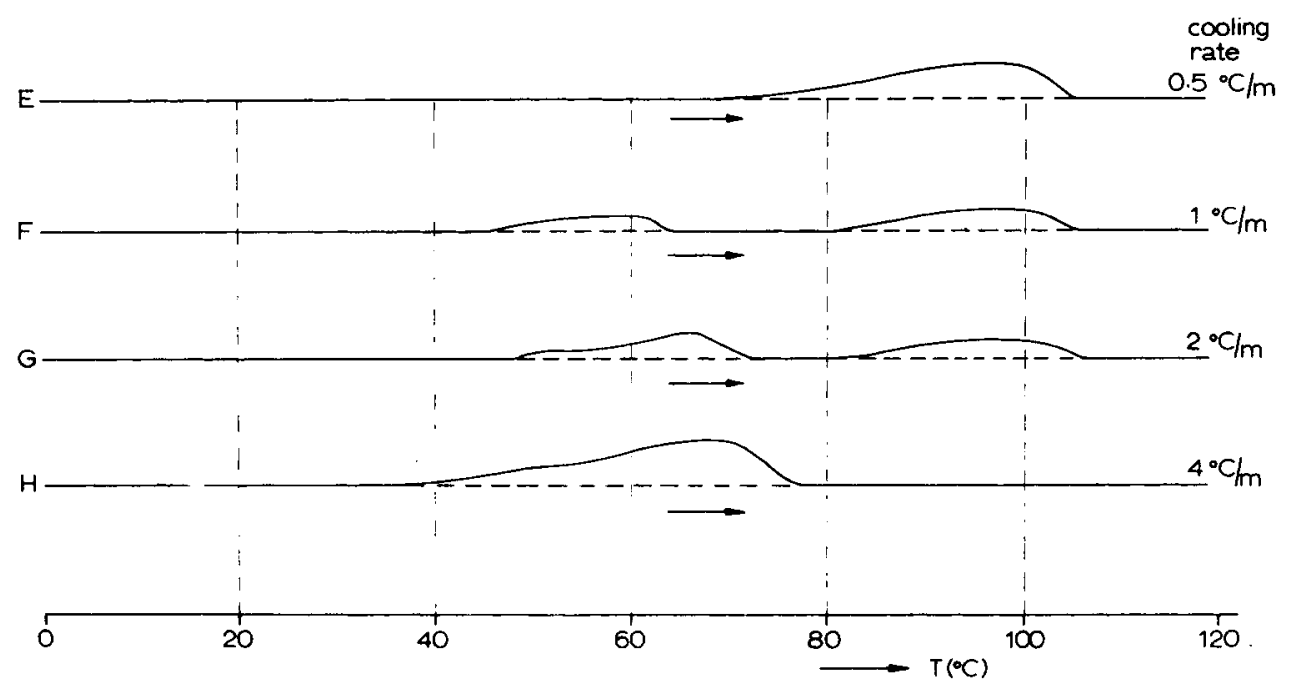

Fig. 2. DSC traces of a $40 \%$ solution of PPO in toluene. Heating after cooling at different rates.

Figure 3 shows the heating curves obtained upon cooling the sample quickly from 120 to $47^{\circ} \mathrm{C}$ in the DSC apparatus and waiting for various periods of time at that temperature. The temperature of $47^{\circ} \mathrm{C}$ was chosen because it is higher than the temperature of appearance of the exotherm (Fig. 1, curve $A$ ). After the waiting period the sample was cooled quickly to $0^{\circ} \mathrm{C}$ and then heated at a rate of $16^{\circ} \mathrm{C} / \mathrm{min}$. Curve $\mathrm{K}$ of Figure 3 is obtained after waiting for several hours at $47^{\circ} \mathrm{C}$, curve $L$ after waiting for $10 \mathrm{~min}$, curve $M$ after waiting for $5 \mathrm{~min}$ and curve $N$ with no waiting time at $47^{\circ} \mathrm{C}$. Curve $N$ is identical with curve $H$ in Figure 2 and with curve $B$ in Figure 1.

As can be seen, waiting at $47^{\circ} \mathrm{C}$ has approximately the same effect as a slower cooling rate (curves $E$ to $H$ in Fig. 2). When the waiting period was introduced at a temperature below the exotherm of curve $A$, Figure 1 , a curve identical to curve $B$ of Figure 1 was obtained, even after waiting for several days. Also, when a solution is cooled quickly from 120 to $0^{\circ} \mathrm{C}$ (below the exotherm of $42^{\circ} \mathrm{C}$ ) and then brought to $47^{\circ} \mathrm{C}$ during various periods of time (up to days), only the endotherm ending at $78^{\circ} \mathrm{C}$ appears on heating.

At other polymer concentrations the same features are observed but the temperature of transition and the recorded heat effects differ. The transition temperatures increase by about $1.23^{\circ} \mathrm{C}$ per percent concentration increase. The heat effects are larger at higher concentrations. For example, at $30 \%$ the heats involved are about $0.3 \mathrm{cal}$ per $g$ of solution and at $40 \% 0.9$ cal per g solution.

\section{DISCUSSION}

Results equivalent to curves $A$ and $B$ of Figure 1 have been found in earlier work. ${ }^{3}$ The exotherm at $42{ }^{\circ} \mathrm{C}$ was assumed to be brought about by spinodal decomposition. The endotherm of $78^{\circ} \mathrm{C}$ was thought to arise from the liquidliquid separated mixture becoming homogeneous. After prolonged waiting below the phase separation temperature, the endotherm at $106^{\circ} \mathrm{C}$ appeared, which was interpreted as the melting of the partly crystallized concentrated phase.

Curve $A$ of Figure 1 is reproducible only after the solution has been reheated 


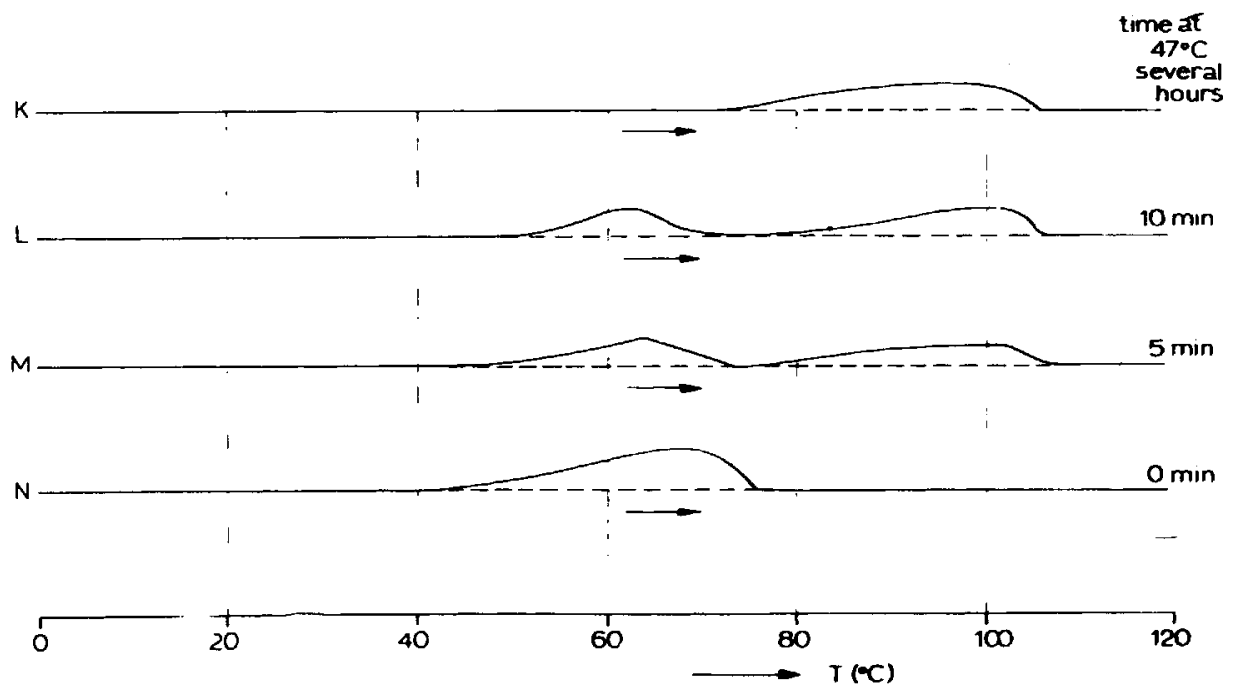

Fig. 3. DSC traces of a $40 \%$ solution of PPO in toluene. Heating after different waiting periods at $47^{\circ} \mathrm{C}$.

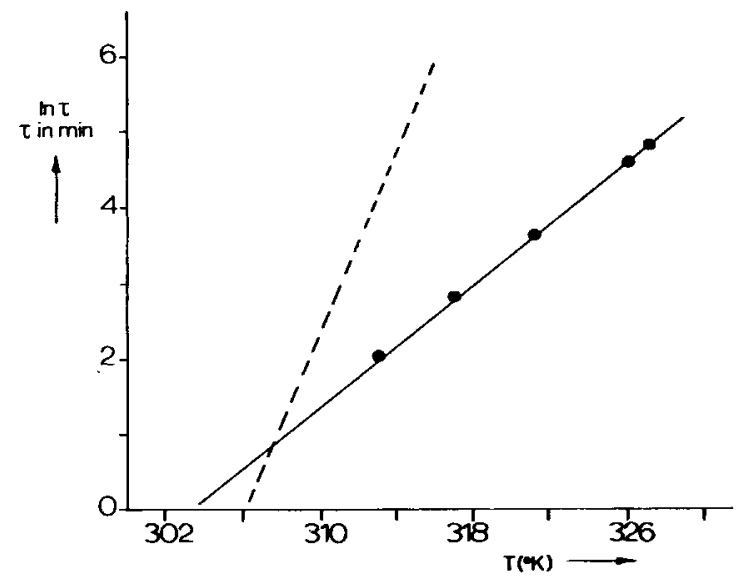

Fig. 4. Hypothetical induction times for low melting crystals (- - -). Measured induction times for a $30 \%$ PPO solution in toluene (••). The induction times were obtained by visual observation by Van Emmerik and Smolders. ${ }^{4}$

to $120^{\circ} \mathrm{C}$. When after a cooling run the solution is only heated to $85^{\circ} \mathrm{C}$ the exotherm on cooling appears at a higher temperature. An explanation can be derived from the assumption that after the first cooling run $(A)$ some nuclei are established which are not destroyed at $85^{\circ} \mathrm{C}$ and cause a "seeded" phase separation during the second cooling run $(C)$. On reheating, the latter phase-separated mixture shows only $106^{\circ} \mathrm{C}$ endotherm. This endotherm can be attributed to the melting of crystallites (pure PPO isolated from such a solution shows a melting peak at $510^{\circ} \mathrm{K}$ in $\mathrm{DSC}^{3}$ ). With reason the nuclei may be supposed to be crystalline in nature, and the phase separation to be crystallization. A remarkable fact is the complete disappearance of the $78^{\circ} \mathrm{C}$ endotherm for this seeded crystallization. This endotherm is also absent when the solution is cooled very slowly (curve $E$ of Fig. 2), and it appears only at higher cooling rates. 
The melting endotherm at $106^{\circ} \mathrm{C}$ is not obtained when the exotherm at 42 ${ }^{\circ} \mathrm{C}$ is brought about by fast cooling, followed by prolonged storage of the phase-separated solutions. This phenomenon does not depend upon the temperature at which the phase separated solution is kept; $0^{\circ} \mathrm{C}$ or $47^{\circ} \mathrm{C}$ (above the temperature of the exotherm) give the same results. This is contrary to earlier findings by Van Emmerik and Smolders. ${ }^{3}$

In view of these results the phase separation at $42^{\circ} \mathrm{C}$ cannot possibly be a liquid-liquid phase separation because: a) In a liquid-liquid phase-separated solution, the crystalline phase melting at $106^{\circ} \mathrm{C}$ must be obtained after some time. b) The endotherm at $78^{\circ} \mathrm{C}$ should not disappear completely when liquid-liquid phase separation has occurred, because only a small fraction of the polymer crystallizes in the concentrated phase.

The crystals melting at $106^{\circ} \mathrm{C}$ originate directly from the solution but nucleation is slow. It now appears that at high cooling rates this nucleation can be overtaken by the nucleation and growth of a lower-melting crystal modification, which is less perfect but has a higher growth rate at the lower temperature. The induction times for the nucleation of both kinds of crystals can be represented schematically as in Figure 4. In curves $F$ and $G$ of Figure 2 and $L$ and $M$ of Figure 3 the growth of the crystals melting at $106^{\circ} \mathrm{C}$ was not complete while the undercooling was proceeding so that the lower-melting crystal could also grow.

The concentration of the polymer in the solution phase has decreased at that stage because of the growth of crystals of the higher melting configuration. This causes the lowering of the melting temperature of the less perfect modification. When the growth of the high-melting modification is complete, the lower-melting one is not found in the temperature range studied (curves $E$ and $K$ ). The phenomena observed can be explained by assuming two crystalline modifications, of which the lower-melting one consists of a less perfect crystalline material.

\section{References}

1. P. T. van Emmerik and C. A. Smolders, J. Polym. Sci., C, 3873 (1972).

2. A. R. Shultz and C. R. McCullough, J. Polym. Sci., A-2, 10, 307 (1972).

3. P. T. van Emmerik and C. A. Smolders, Europ. Polym. J., 9, 293 (1973).

4. P. T. van Emmerik and C. A. Smolders, Europ. Polym. J., 9, 931 (1973).

Received January 7, 1976

Revised July 6, 1976 